\title{
Air Abrasion: Truly Minimally Invasive Technique
}

\author{
${ }^{1}$ Imran Farooq, ${ }^{2}$ Zonera Imran, ${ }^{3}$ Umer Farooq \\ ${ }^{1}$ Postgraduate Student, Department of Dental Physical Sciences Unit, Queen Mary University of London, London, United Kingdom \\ ${ }^{2}$ Faculty, Department of Oral Surgery, Homerton University Hospital, London, United Kingdom \\ ${ }^{3}$ Postgraduate Student, Department of Public Health, Glyndŵr University, Wales, United Kingdom
}

\begin{abstract}
Correspondence: Imran Farooq, Postgraduate Student, Department of Dental Physical Sciences Unit, Queen Mary University of London, London, United Kingdom, e-mail: drimranfarooq@gmail.com

\section{ABSTRACT}

Minimally invasive dentistry concept is now an essential part of dental procedures. Many novel materials and techniques have now been developed that are in line with the MI (minimal intervention) philosophy. One such technique is air abrasion. An attempt has been made in this article to cover all the aspects of air abrasion and to remove the misconceptions present about this technique.

Keywords: Air abrasion, Minimally invasive dentistry, Bioactive glasses.
\end{abstract}

\section{INTRODUCTION}

Minimally invasive dentistry is not a very new concept but still many dental practitioners do not know its importance. Many novel dental materials and techniques now work on the principle of minimal invasion. One such technique is air abrasion.

Air abrasion was first described by Black (1945). ${ }^{1}$ His aim was to develop a technique that is effective, works on the principles of minimal invasion and is more tissue preserving. ${ }^{2}$ During 1950s, in Michigan (USA), the air abrasion technique gained popularity and a program was designed to teach the air abrasion technique to dentists. ${ }^{3}$ McGehee WH (1956) wrote a textbook in 1950s which even contained information about the applications of air abrasion. ${ }^{4}$ Therefore, air abrasion is not a new technique. Since amalgam was the most popular restorative material those days, this technique did not gain much attention because it lacked the ability to accurately prepare cavity margins and there were concerns regarding the dust particles affecting the eyes of the patients and the dentists. ${ }^{5}$ Also, the development of air turbine handpiece made cavity preparation easy and quicker. ${ }^{6}$

With the introduction of the minimally invasive dentistry concept, high volume suction and development of new materials that retain by bonding with the tooth tissue, air abrasion technique has experienced a rebirth. ${ }^{7}$ Air abrasion's reevaluation has been possible because of the change in the viewpoint of diagnosing and managing caries. ${ }^{8}$

Many dental practitioners are using air abrasion nowadays with $27 \mu \mathrm{m}$ alumina particles. Air abrasion technique utilizes alumina particles for the removal of tooth tissue and it has no vibration and less heat generation, when compared with a conventional high-speed handpiece. ${ }^{9}$

\section{MECHANISM OF ACTION}

Air abrasion utilizes kinetic energy for the removal of caries and alumina particles which are expelled by air pressure at high velocity and the particles abrade the surface when they strike it without any significant heat or noise production. ${ }^{10}$

The formula for kinetic energy is $1 / 2 \mathrm{mv}^{2}$, where $\mathrm{m}$ represents mass and $v$ represents velocity. If the surface is hard, the particles take away small amount of surface and, if it is soft, energy is captured by the material and the particles bounce off. ${ }^{11}$

The principal action of air abrasion is end cutting. ${ }^{9}$ So, the access has smaller diameter but the cavities produced are deep. This action is quite different from conventional burs as they produce wider access with shallow cavities. ${ }^{12}$ Air abrasion produces a surface roughness which is ideal for the materials that bond directly to the tooth surface. ${ }^{13}$

The use of air abrasion may also remove the requirement for etching the enamel surface with acid when fissure sealants are used..$^{14} \mathrm{~A}$ total of $27 \mu \mathrm{m}$ alumina particles are only second to diamond in terms of abrasivity. ${ }^{15}$ The hardness of the alumina particles is 16 to $18 \mathrm{GPa}^{16}$

Motisuki C et al (2006) performed a study on extracted human teeth to assess which particle size in air abrasion system removes carious dentine with maximum conservation of tooth structure. 27, 50 and $125 \mu \mathrm{m}$ alumina particles were used and it was concluded that 27 and $50 \mu \mathrm{m}$ alumina particles remove less sound tissue as compared with $125 \mu \mathrm{m}$ particles, when carious dentine is removed using air abrasion. ${ }^{17}$

If water is added to the air abrasion system, it creates a water shroud and the water shroud not only prevents dust formation but also decreases the amount of alumina attached to the tooth surface after the procedure. ${ }^{18}$ 


\section{Control of Cutting Efficiency}

Cutting efficiency is dependent on various factors, like particle size and shape, distance of the tip of the handpiece from the tooth surface, feed rate (powder flow), length of cutting time and air pressure. ${ }^{19}$

Horiguchi et al (1998) used aluminum oxide powder, glass beads, crushed glass powder and crushed polycarbonate resin powder to evaluate the cutting ability of air abrasion when it was used to cut intact enamel and dentine and concluded that crushed glass powders which were angular shaped cut three times more efficiently, when compared with glass bead particles which were spherical in shape. ${ }^{20}$

Banarjee A et al (2008) carried out a study using four different air abrasion units to investigate the effect of powder fill on the flow rate and cutting efficiency and concluded that the flow rate was different for each air abrasion unit when the volume of alumina powder was changed. It was, therefore, proposed that a constant level of alumina powder should be maintained to attain a constant cutting. ${ }^{21}$

It is suggested that air pressure for tooth preparation should be between 40 to 60 psi (2.75-11.03 Bars). ${ }^{22}$

Alumina particle sizes for air abrasion range from 27 to $50 \mu \mathrm{m}$ in diameter. The operating distance should be between 0.5 to $2 \mathrm{~mm}$. If the distance is more than $2 \mathrm{~mm}$, it results in decreased cutting. ${ }^{6}$

Kinetic energy of the transferred particles is decreased, when the velocity is decreased which results in reduced abrasiveness of the surface. ${ }^{23}$ Increasing the alumina particle size (mass) from 27 to $50 \mu \mathrm{m}$ increases the kinetic energy being transferred to the surface by a factor of 8 . Although this can increase the cutting efficiency, it can also cause increased patient discomfort. Particle size of $34 \mu \mathrm{m}$ should be used to remove enamel and $27 \mu \mathrm{m}$ should be used to remove caries. ${ }^{24}$

\section{Rotary Cutting vs Air Abrasion}

Rafique S et al (2003) proposed that patients feel reduced pain with air abrasion as compared with other conventional methods. ${ }^{25}$

Rotary cutting instruments can increase the temperature of the tissue by 300 to $400^{\circ} \mathrm{C} ;{ }^{26}$ however, the temperature changes with air abrasion are minimum $\left( \pm 2^{\circ} \mathrm{C}\right)$, so the risk of cracking is also decreased. ${ }^{23}$ The shape of the bur used with high-speed handpiece is also important as, if it is less then concentric, it will cause enamel cracking. ${ }^{27}$

Hicks MJ et al (2001) studied the development of secondary caries after using conventional handpiece and an air abrasion technique for cavity preparation in teeth. The teeth were restored with composite resin and caries were introduced by exposing the teeth to an artificial caries medium. Polarized light microscopy was used to assess the presence and extent of the lesion and it was concluded that both techniques offer similar defence against secondary caries. ${ }^{28}$

Christensen (1996) compared the use of air abrasion and rotary cutting for cutting cavities in teeth and suggested that air abrasion has various advantages over rotary cutting, such as reduced noise production, no vibration and less need for anesthesia. All these advantages make this technique particularly useful for children and for the patients who have a fear of anesthesia and noise. Because of these indications, air abrasion has an edge over rotary cutting because it is in line with the principles of minimally invasive dentistry. ${ }^{29}$

\section{Specific Indications of Air Abrasion Technique}

Air abrasion is particularly important in certain areas. It was suggested that air abrasion can be used to diagnose and treat early lesions. It was also proposed that the cavities prepared with air abrasion are better for bonded restorations as they give rounded contours which decrease the risk of fracture of restorations. ${ }^{30}$

This technique is particularly useful for the removal of defects that are presented on superficial surface of enamel as it results in decreased loss of normal tooth structure when compared with a high-speed handpiece. ${ }^{31}$

This technique can also reduce the microleakage of the sealants because it provides a very rough enamel surface which improves the retention of bonding materials. ${ }^{32}$

Air abrasion can also be used to remove old restorations by increasing the air pressure. ${ }^{6}$ When air abrasion is used, the need for local anesthesia is also minimized. ${ }^{20} \mathrm{~A}$ total of 80 to $95 \%$ of the patients treated with air abrasion do not need anesthesia. This not only saves valuable clinical time of the practitioner but patient visits can also be decreased as multiple quadrants of patients oral cavity can be treated in a single visit. Air abrasion is very useful for the removal of composite and glass ionomer cement restorations. ${ }^{31}$

Cook RJ et al (2001) called air abrasion, the technique of choice for the removal of faulty composite restorations. ${ }^{33}$

\section{Limitations of Air Abrasion Technique}

Air abrasion is not very effective for the removal of amalgam restorations. Also, there are concerns regarding the amount of mercury released during the removal of amalgam restoration. ${ }^{34}$ Practitioners should remain careful when they use air abrasion as there is loss of tactile sensation and it can readily cut hard tissues. $^{27}$

Air abrasion cannot remove deep carious lesions as it cannot cut soft substances. ${ }^{6}$

Banerjee et al (2000) has, however, proposed that softened dentine can be removed with air abrasion, when a mixture of alumina and hydroxyapatite is used. ${ }^{35}$

Use of rubber dam and high vacuum suction for the patient and eye wear for the practitioner is highly recommended to prevent the dust from being inhaled and causing an injury to the eye respectively. ${ }^{24}$

\section{Bioactive Glasses and Air Abrasion}

Many dental practitioners are concerned about the toxicity of alumina particles which can be inhaled during the procedure. 
Bioactive glasses can replace alumina in air abrasion system. ${ }^{36}$ But bioactive glasses are brittle and they fracture after coming in contact with hard dentine surface. The hardness of bioactive glasses is less than alumina but they can cause remineralization of the surface unlike alumina. Therefore, bioactive glasses of different composition and hardness should be produced to test their cutting efficiency. ${ }^{18}$

\section{CONCLUSION}

Minimally invasive dentistry is the need of the hour, and air abrasion is a technique that is truly in line with the minimal intervention philosophy. Air abrasion is now being used by many dental practitioners in USA and it is still gaining popularity in Europe.

\section{REFERENCES}

1. Black RB. Technique for nonmechanical preparation of cavities and prophylaxis. J Am Dent Assoc 1945;32:955-65.

2. Rinaudo, Cochran, Moore. The effect of air abrasion on shear bond strength to dentin with dental adhesives. Oper Dent 1997; 22:254-59.

3. Paolinelis G, Banarjee A, Watson TF. An in vitro evaluation of the efficiency of an air-abrasion system using helium as a propellant. Dent Mater 2009;25:1442-45.

4. McGehee WH. A textbook of operative dentistry. Philadelphia McGraw-Hill 1956.

5. Boyde A. Air polishing effects on enamel, dentine, cementum and bone. Br Dent J 1984;156:287-91.

6. Hegde Vivek S, Khatavkar Roheet A. A new dimension to conservative dentistry: Air abrasion. J Conserv Dent 2010;13(1): 4-8.

7. Walmsley AD. Transfer technology in dentistry. Br Dent J 2003; 194:226-27.

8. Banerjee A, Watson TF, Kidd EAM. Dentine caries: Take it or leave it? Dent Update 2000;27:272-76.

9. Black RB. Application and re-evaluation of the air abrasive technique. J Am Dent Assoc 1955;50:408-14.

10. Carol Anne, Mary Ellen. Minimally invasive dentistry. JADA 2003;134:87-95.

11. Lambrechts $\mathrm{P}$, et al. Air-abrasion enamel microsurgery to treat enamel white spot lesions of traumatic origin. J Esth Rest Dent 2002;14(3):167-87.

12. Wilson Nairn. Minimally invasive dentistry — the management of caries. London: Quintessence 2007;7:91-92.

13. Chan DC, Summitt JB, Garcia-Godoy F, Hilton TJ, Chung KH. Evaluation of different methods for cleaning and preparing occlusal fissures. Oper Dent 1999;6:331-36.

14. Myers TD. Advances in air abrasive technology. Journal of California Dental Association 1994;22:41-44.

15. Laurel K, Lord W, Beck M. Kinetic cavity preparation effects on bonding to enamel and dentin. J Dent res 1993; Special issue, Abstract 1437.

16. Krell A. Handbook of ceramic hard materials. Riedel R (Ed). Willey-VCH 2000.

17. Motisuki C, Lima, Bronzi, Spolidorio, Santos-Pinto. The effectiveness of alumina powder on carious dentin removal. Operat Dent 2006;31(3):371-76.
18. Paolinelis G, Banarjee A, Watson TF. An in vitro investigation of the effect and retention of bioactive glass air-abrasive on sound and carious dentine. J Dent 2008;36:214-18.

19. Reyto R. Lasers and air abrasion. New modalities for tooth preparation. Dent Clin North Am 2001;45(1):189-206.

20. Horiguchi S, Yamada T, Inokoshi S, Tagmi J. Selective caries removal with air-abrasion. Op Dent 1998;23:236-43.

21. Banerjee A, Mohsin Uddin, Paolinelis G, Watson TF. An investigation of the effect of powder reservoir volume on the consistency of alumina powder flow rates in dental air-abrasion devices. J Dent 2008;36:224-27.

22. Banerjee A, Thompson ID, Watson TF. Minimally invasive caries removal using bio-active glass air-abrasion. J Dent 2011;39:2-7.

23. Black RB. Air abrasive: Some fundamentals. J Am Dent Assoc 1950;41:701-10.

24. Graham Mount. Minimal intervention dentistry: Cavity classification and preparation. J Minim Interv Dent 2009;2(3).

25. Rafique S, Fiske J, Banerjee A. Clinical trial of an air abrasion chemomechanical operative procedure for the restorative treatment of dental patients. Caries Res 2003;37:360-64.

26. Lloyd B, Chiristensen D, Brown W. Energy inputs and thermal stresses during cutting in dental materials. The cutting edge: Interfacial differentials of cutting and grinding. In: Peralman S (Ed). Procs. Am. Society for Adv Sci US department of Health Publications (NIH) 1976:175-202.

27. Watson TF, Pilecki, Cook RJ, Azzopardi, Paolinelis G, Banerjee A, et al. Operative dentistry and the abuse of dental hard tissues: Confocal Microscopical Imaging of Cutting. Operative Dentistry 2008;33(2):215-24.

28. Hicks MJ, Parkins FM, Flaitz CM. Kinetic cavity preparation effects on secondary caries formation around resin restorations: A polarized light microscopic in vitro evaluation. ASDC J Dent Child 2001;68(2):115-21,80,142.

29. Christensen GJ. Cavity preparation cutting or abrasion? J Am Dent Assoc 1996;127:1651-54.

30. Rainey JT. Air abrasion: An emerging standard of care in conservative operative dentistry. Dent Clin North Am 2002; 46(2):185-209.

31. White JM, Eakle SW. Rationale and treatment approach in minimally invasive dentistry. J Am Dent Assoc 2000;131:18S.

32. Wright, Hatibovic-kofman, Millenaar, Braverman. The safety and efficacy of treatment with air abrasion technology. Int J Paediat Dent 1999;9:133-140.

33. Cook RJ, Azzopardi A, Thompson ID, Watson TF. Real time confocal imaging during active air-abrasion substrate cutting. J Micro 2001;203(2):199-207.

34. OSHA regulations (Standards-29 CFR). US Department of Labour, Occupational Safety and Health Administration. 2007 Apr 18, Available from: http://www.osha-slc.gov/OshStd_data/ 1910_1000_TABLE_Z-1html.

35. Banerjee A, Kidd EAM, Watson TF. In vitro evaluation of five alternative methods of carious dentine excavation. Caries Res 2000; 34:144-50.

36. Banerjee A, Paolinelis G, Socker M, McDonald F, Watson TF. An in vitro investigation of the effectiveness of bioactive glass air-abrasion in the selective removal of orthodontic resin adhesive. Eur J Oral Sci 2008;116:488-92. 